\title{
"Fragmentos de memorias rescatadas". Proceso participativo de definición de criterios para la restauración del Muro de Mosaicos de Villa Grimaldi, en Chile
}

"Fragments of Rescued Memories". Participatory Process for the Definition of the Criteria for the Restoration of the Villa Grimaldi Mosaic Wall, Chile

\section{Omar Sagredo Mazuela}

Área Museo de la Corporación Parque por la Paz Villa Grimaldi, Chile omar.sagredo@villagrimaldi.cl

\section{Resumen}

El presente INFORME describe y analiza el proceso de definición cualitativa de los criterios para la restauración del Muro de Mosaicos del sitio de memoria Parque por la Paz Villa Grimaldi y, en específico, los encuentros participativos en los que exprisioneros políticos, pedagogos de la memoria y representantes de la comunidad local dialogaron sobre las alternativas de restauración. Estas instancias, basadas en la metodología de museología participativa, determinaron tanto la configuración definitiva del muro como el título de la obra. Para concluir, se destaca este proceso como una experiencia de sensibilización y sociabilización respecto de la intervención democrática del patrimonio cultural en derechos humanos.

\section{Palabras clave}

Villa Grimaldi; memoria; museología participativa; Peñalolén; Chile

\section{Abstract}

This REPORT describes and analyzes the qualitative definition process of the criteria for the restoration of the Mosaic Wall in the memorial site, Villa Grimaldi Peace Park and, in particular, of the participatory encounters in which the ex-political prisoners, memory pedagogues, and representatives of the local community discussed on the restoration alternatives. These instances, based on the methodology of participatory museology, determined both the definitive configuration of the wall as well as the title of the work. In conclusion, this process is highlighted as a sensibilization and socialization experience with regard to democratic intervention of cultural heritage on human rights. 


\section{Keywords}

Villa Grimaldi; memory; participatory museology; Peñalolén; Chile

\section{Introducción}

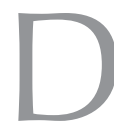
urante la dictadura cívico-militar que gobernó Chile entre el 11 de septiembre de 1973 y el 11 de marzo de 1990, los organismos represivos asesinaron a 2123 opositores e hicieron desaparecer a 1092, mientras que 4018 más sufrieron torturas por razones políticas. Estas acciones criminales se ejecutaron, en su mayoría, en recintos especialmente habilitados (Santos-Herceg 2016: 167-168).

Actualmente, el rescate, la protección y promoción de la memoria de estos espacios utilizados por organismos represivos es una de las principales motivaciones del movimiento de derechos humanos en Chile (Aguilera 2013: 3), así como también una de las más relevantes políticas públicas de memoria efectuadas por el Estado chileno desde el retorno a la democracia (Cabeza 2017: 15-18), donde, en tanto se trata de procesos de reparación y testificación de las violaciones a los derechos humanos, ha destacado la importancia de la articulación social para la gestión de espacios de memoria (Lawner 2017: 22-24).

El presente INFORME evidencia lo anterior y se centra en el mecanismo participativo de definición de los criterios para la restauración del Muro de Mosaicos de Villa Grimaldi, que, como parte de la arquitectura original de este recinto, fue testigo de las atrocidades ocurridas en el lugar mientras funcionó como centro represivo durante la dictadura cívico-militar chilena. Luego del terremoto que asoló al país en febrero de 2010, el muro se derrumbó. Durante 2017, el Área Museo del Parque por la Paz (equipo de profesionales encargado de la conservación y la gestión patrimonial de este sitio de memoria) organizó la recuperación de dicho vestigio por medio del proyecto "Puesta en valor de la memoria histórica de Villa Grimaldi". Su objeto general fue recuperar y restaurar el Muro de Mosaicos y, a su vez, generar una instancia de sensibilización y promoción de la memoria histórica del sitio mediante ejercicios de memoria social. La opción elegida de restauración fue resultado de cuatro encuentros participativos en los que, apegado al uso de los principios de la museología participativa, un conjunto de actores representativos de la gestión y uso del Parque por la Paz acordó qué memorias destacar y cómo representarlas en el muro.

Concretamente, este informe da cuenta de la descripción histórica de Villa Grimaldi, de los conceptos y perspectivas teóricas que sirvieron de referencia para la ejecución del proyecto, del análisis de resultados de los encuentros participativos (a partir de dos dimensiones: rescate de memorias y propuestas de transmisión) y, finalmente, de algunas reflexiones planteadas a modo de conclusiones.

\section{Antecedentes históricos}

Luego del golpe de Estado del 11 de septiembre de 1973, comenzó una ola represiva sobre funcionarios del gobierno de la Unidad Popular, miembros de los partidos políticos y organizaciones sociales que lo conformaron o apoyaron, así como contra el amplio sector de la población que simpatizaba con el proceso liderado por el presidente Salvador Allende (Yocelevzky 2002: 109). En la segunda ola represiva, ocurrida entre los años 1974 y 1978, la dictadura cívico-militar desplegó una fórmula de represión clandestina, a cargo de la Dirección de Inteligencia Nacional (DINA), en la que reemplazó el uso de espacios abiertos y públicos por lugares privados y secretos. Sobre aquella lógica, a comienzos de 1974, la DINA decidió apropiarse del centro de actos y restaurante Paraíso Villa Grimaldi, otorgándole el título de "Cuartel Terranova" (Salazar 2013: 97).

Se estima que entre 1974 y 1978 estuvieron secuestradas en este recinto, aproximadamente, 4500 personas, 22 de las cuales fueron ejecutadas y 219 desaparecidas por los agentes de la DINA. Durante el periodo represivo, algunos detenidos recuerdan la existencia del Muro de Mosaicos, ya que éste formaba parte del perímetro que rodeaba un costado del espacio de las celdas.

Hacia 1978, luego de que la DINA se disolvió y fue reemplazada por la Central Nacional de Informaciones (CNI), Villa Grimaldi terminó sus prácticas represivas (Del Pozo 2018: 157). A finales de los años ochenta, el último jefe de la CNI, el general de Ejército Hugo Salas, le vendió la propiedad a una constructora conformada por sus parientes, que rápidamente demolió los principales edificios del lugar con la intención de construir un conjunto habitacional. Los vecinos de Villa Grimaldi, a los que pronto se sumaron exdetenidos y familiares de ejecutados políticos y detenidos desaparecidos del recinto y comunidades cristianas de base de la zona, se organizaron en la Asamblea Permanente de los Derechos Humanos Peñalolén-La Reina con el propósito de frenar las labores de demolición.

Las acciones de protesta y la denuncia de la asamblea obtuvieron resultados positivos cuando, al término de 1993, el Estado decidió expropiar Villa Grimaldi y entregársela en comodato por 50 años a los integrantes de este colectivo ciudadano. En 1996, se conformó la Corporación Parque por la Paz Villa Grimaldi con el objeto de gestionar la apertura de un espacio de memoria y promoción de los derechos humanos, Ilamado Parque por la Paz. Su apertura oficial fue el 22 de marzo de 1997, teniendo como principal característica un diseño simbólico (López 2010: 62-63). 


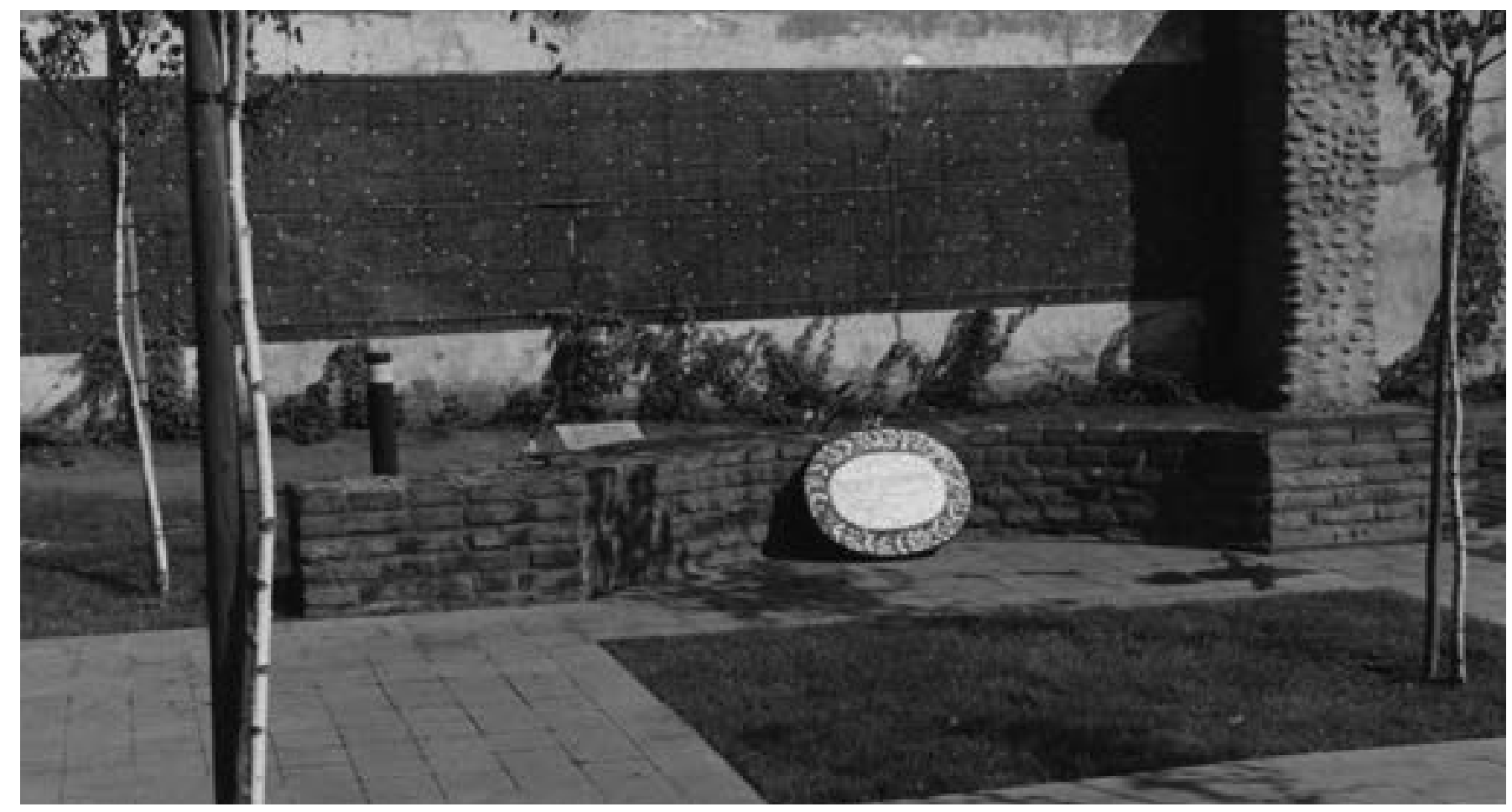

FIGURA 1. Muro de Mosaicos de Villa Grimaldi. Inauguración Parque por la Paz (Fotografía: Cecilia Bottai, 1996; fuente: Archivo Documental, Corporación Parque por la Paz Villa Grimaldi; cortesía: Corporación Parque por la Paz Villa Grimaldi, Chile).

Ante la ausencia de documentación oficial relativa a las dinámicas represivas, los vestigios que sobrevivieron a la demolición del sitio fueron claves para la reconstrucción espacial de su historia, entre los que el Muro de Mosaicos fue de gran relevancia, en tanto que permitió determinar la ubicación de las antiguas celdas. La Figura 1 muestra el muro al momento de la inauguración del Parque por la Paz. Luego del terremoto que asoló la zona centro-sur en febrero de 2010, el muro se derrumbó. De acuerdo con la investigación que permitió la creación del guion de la audioguía, se estableció que:

Tras el banco de la solidaridad, se encontraba un muro perimetral original de la antigua residencia de Villa Grimaldi, el cual se derrumbó con el terremoto del 27 de febrero de 2010. En él se encontraba una cubierta de mosaicos que algunos sobrevivientes pudieron reconocer y recordar que correspondía al muro de algunas celdas, puesto que al tocarlo, lo sentían como una superficie dura y fría donde alguna vez se apoyaron para enfriar sus cuerpos durante el verano [Corporación Parque por la Paz Villa Grimaldi 2010].

Durante 2017, se ejecutó en el Parque por la Paz una serie de acciones de restauración en diferentes vestigios y soportes museográficos con la finalidad de poner en valor y recuperar espacios patrimoniales fundamentales para la función conmemorativa del sitio. Entre los elementos por restaurar, el Muro de Mosaicos fue el único que estuvo sujeto a un proceso de recuperación de memorias que podría alcanzar el formato de trabajo definitivo.

\section{Apuntes conceptuales}

Las definiciones sobre el concepto y la gestión del patrimonio utilizadas en este proyecto corresponden a la de patrimonio intangible y cultural, destacando el rol de los sujetos en tanto creadores o productores del patrimonio (Garcés 2009: 171). De acuerdo con la Organización de las Naciones Unidas para la Educación, la Ciencia y la Cultura (UNESCO s. f.: 4-6), este tipo de patrimonio posee cuatro dimensiones constitutivas: es tradicional y contemporáneo; es integrador (ya que contribuye a crear un vínculo entre el pasado y el futuro por medio del presente); es representativo, y está basado en la comunidad (puesto que sólo puede ser reconocido por las comunidades, grupos o individuos que lo crean, mantienen y transmiten).

Ahora bien, considerando esta definición general, la ejecución concreta del proyecto se basó en dos conceptos específicos: "patrimonio de la atrocidad y el horror", y "museología participativa". Respecto de la primera dimensión, se entiende como "patrimonio del horror" aquel que simboliza una enseñanza para la no repetición, en tanto representación del daño sufrido por la sociedad en su conjunto. Este patrimonio es un espacio donde las víctimas encuentran, reconociendo el valor histórico en los vestigios, un lugar de reparación (Alegría 2011: 306-308).

En ese sentido, una de las mayores expresiones de este tipo de patrimonio en América Latina son los sitios de memoria. Su constitución implica el rescate, salvaguardia, señalación, apertura, transmisión de la memoria y resignificación (Feld 2011: 13). En Chile, los avances respecto de 


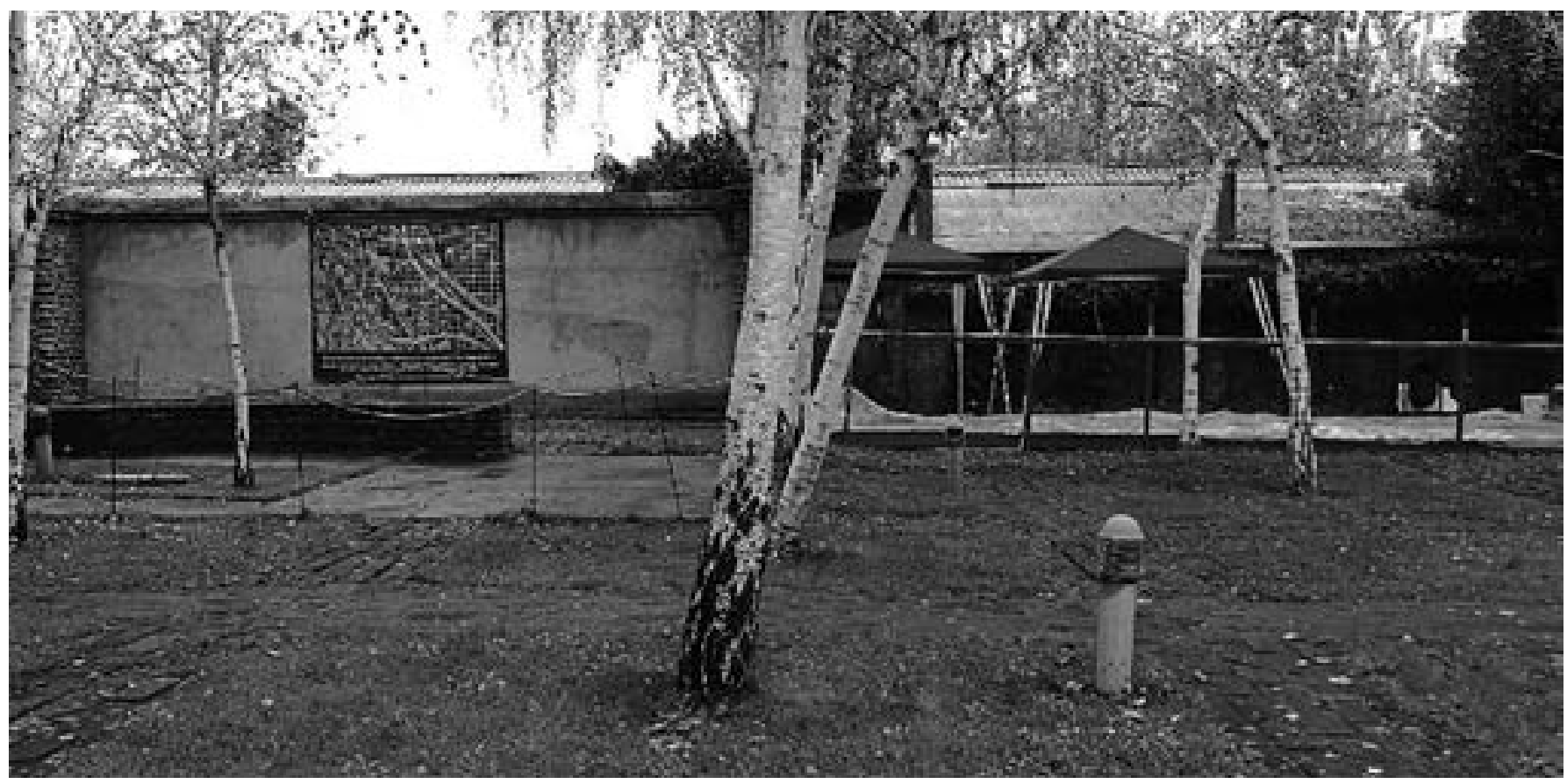

FIGURA 2. Muro de Mosaicos de Villa Grimaldi. Preparativos para la restauración (Fotografía: Luis Arellano, 2017; cortesía del autor).

los sitios de memoria se reflejan en el incremento de sitios declarados monumentos nacionales en los últimos años (Cabeza 2017: 16-17), concomitante a la creación de novedosas corrientes de trabajo arquitectónico y museístico (Silva y Rojas 2011: 80-84).

Por otra parte, en términos de preservación del patrimonio de la memoria de las violaciones a los derechos humanos, en Chile, se han organizado metodologías de trabajo que involucran activamente a la sociedad, principalmente, familiares de víctimas, exdetenidos y vecinos, en el marco de procesos de significación social (Lawner 2017: 22-24). En este sentido, la metodología de la museología participativa se ha utilizado con frecuencia en diversos museos (Orellana 2007: 202-205; Aguilera 2012: 34-35), en el marco de la perspectiva de la nueva museología en cuanto explicación de la función de la memoria y la educación en los sitios como intervención espacial orientada a los intereses de la comunidad asociada a su historia (Aguilera 2011: 101-102).

En específico, este proyecto utilizó la museología participativa con el objeto de incorporar a las comunidades que constituyen el uso social del Parque por la Paz en la gestión restaurativa del sitio. Aprovechando las propiedades reflexivas y democratizadoras de esta metodología (Orellana 2007: 202-203), se buscó integrar propuestas, recoger inquietudes y definir temas relevantes que se incorporarían en la estrategia restaurativa. El planteamiento utilizado comprendió la realización de encuentros participativos, en los cuales se evaluó el impacto de la memoria colectiva (Lavabre 2018: 279) —representada por la comunidad local, pedagogos de la memoria y expresos políticos - en el entendimiento del patrimonio, expresado aquél en la forma que debía adoptar la restauración del Muro de Mosaicos.

\section{Ejercicios de memoria: definición democrática del formato de restauración}

La restauración del Muro de Mosaicos se determinó como resultado de un acuerdo que debía surgir de la deliberación de los principales actores inmersos en la transmisión de la memoria y el uso social del Parque por la Paz: exdetenidos, ${ }^{1}$ educadores ${ }^{2}$ y comunidad local. ${ }^{3}$ Este as-

\footnotetext{
${ }^{1}$ El Parque por la Paz Villa Grimaldi es administrado por una asamblea de socios, compuesta, en su mayoría, por exdetenidos del recinto. Un número importante de ellos ha dedicado sus esfuerzos a la transmisión de la memoria y la educación en derechos humanos, y ha participado frecuentemente en las actividades educativas realizadas en el sitio. La invitación a intervenir en los encuentros participativos se extendió a este grupo.

${ }^{2}$ Desde 2009, el Parque por la Paz Villa Grimaldi cuenta con un Área Educación, la cual está encargada de diseñar y efectuar diversas actividades pedagógicas en el campo de la educación en derechos humanos. Una de las principales acciones desarrollas son los recorridos pedagógicos, instancias donde los educadores del sitio transmiten a la comunidad estudiantil la memoria de las violaciones a los derechos humanos cometidas en el recinto y relacionan hechos y situaciones del presente con las vulneraciones del pasado (Bascuñán 2018: 110-112).

${ }^{3}$ La gente de Peñalolén (comuna donde se encuentra el Parque por la Paz) utiliza frecuentemente las dependencias del sitio para reuniones y actividades culturales y religiosas. En los encuentros reseñados, participaron integrantes de la junta de vecinos, de la agrupación de adultos mayores y de las comunidades cristianas de base.
} 
pecto se definió a partir de una metodología de museología participativa denominada "ejercicios de memoria", a través de la cual se discutieron dos opciones de restauración. La primera, reconstruir el muro en su totalidad, reemplazando las piezas faltantes por nuevas, y la segunda, reponerlo parcialmente, sólo con los fragmentos originales, dejando a la vista espacios vacíos. La Figura 2 presenta el estado del muro al momento de iniciar los encuentros.

Durante el mes de julio de 2017, se realizaron cuatro encuentros, en los que participó un total de veinticinco personas. La primera, segunda y tercera instancia (en las que estuvieron exdetenidos, educadores y comunidad local) comenzaron con la presentación técnica, por parte del equipo del Área Museo, de las mencionadas propuestas de restauración. Luego, conociendo las impresiones de los participantes, se inició el diálogo. Al cierre de la actividad (con un tiempo de trabajo que bordeó, en promedio, dos horas por sesión), se procedió a realizar un balance sobre las ideas y reflexiones planteadas, señalando qué alternativa había contado con mayor apoyo.

En la práctica, en las deliberaciones respecto de las opciones, los debates se reforzaron con base en razonamientos relativos al tipo de relato que debía expresar el muro restaurado. Los siguientes fragmentos de las argumentaciones presentadas en los encuentros participativos muestran las diferencias acerca de los aspectos por destacar.

Yo creo que este muro puede tener dos valores. Puede tener un valor histórico, por la materialidad [...] esto, que es una obra que no tiene ningún valor de ningún tipo, o sea, es un revestimiento, antes de que esto fuera Cuartel Terranova, ése era revestimiento que podía estar en veinte mil partes. No tenía ningún valor. Pero después, esto toma un valor, y es un valor histórico [exdetenido de Villa Grimaldi 2017a].

¿Qué representa el muro? El muro representa momentos de dos cosas: de mucha angustia y de mucha solidaridad y de afecto. Porque permitió que los presos se reconocieran cuando había pequeños espacios para que compartieran, pero además significó, digamos, éste era el muro de una celda, por lo menos, en mi experiencia [exdetenido de Villa Grimaldi 2017a].

El foco principal es poder señalar, a través de esa materialidad, cuál es la historia que contiene, de cómo están asociadas las memorias [...]. Hay algún aspecto que podemos dialogar, que el sitio, bueno no sólo este sitio, sino cualquier sitio de memoria, a propósito de la recuperación y de los vestigios que apoyan a estas memorias, también tiene que dialogar a propósito de la posibilidad de los cuestionamientos de aquella veracidad que se pone en juego a través del objeto [educadora de Villa Grimaldi 2017a].

Yo creo que si aquí hay un tema importante, es la memoria. Entonces, a mí se me ocurre [...], a lo mejor hacer algo que recupere la memoria de este terremoto, que digamos, un

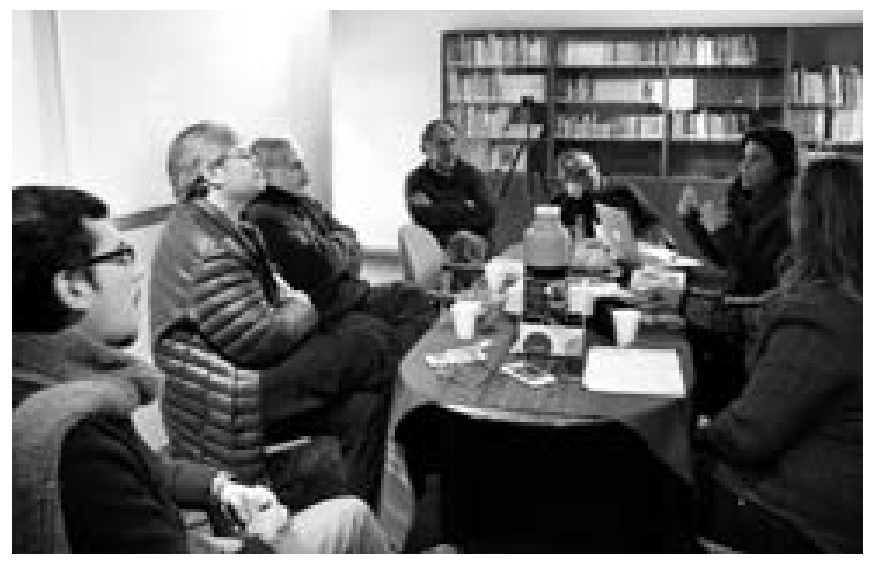

FIGURA 3. Cuarto encuentro participativo. Proceso de restauración del Muro de Mosaicos de Villa Grimaldi (Fotografía: Karla Garay, 2017).

terremoto físico, pero nosotros vivimos un terremoto social representado en el golpe de Estado y la dictadura; vivimos un dolor tan grande, una destrucción tan grande de nuestras vidas, de nuestras sociedades, de nuestras familias, de todo lo que éramos y que fue también un megaterremoto. Entonces, a lo mejor, tener una parte para recuperar, pero tener otra parte que dé cuenta, efectivamente, cómo se engancha este terremoto físico con ese otro terremoto que se vivió [representante comunidad local 2017a].

Estos planteamientos señalan los diferentes énfasis que cada actor propuso asociar con el Muro de Mosaicos: el valor histórico, la asignación de propiedades (entre las que destacaron "solidaridad", "afecto" y "angustia"), la veracidad material y la relación de memorias traumáticas de la sociedad chilena. A continuación, relacionando sus ideas sobre la relevancia de las memorias, los participantes hicieron propuestas sobre la restauración. La Figura 3 muestra el debate generado en el cuarto y último encuentro, instancia en la que se tomó la decisión final.

Entonces, lo que le da sentido al lugar es su historia, es lo que se vivió acá y por eso también nosotros éramos parte de un grupo muy pequeño, que éramos los amantes de la Villa Grimaldi y no del Parque. Porque la Villa Grimaldi en sí te entrega los elementos básicos y necesarios para decir: éste es un lugar histórico, es un lugar de memoria [exdetenido de Villa Grimaldi 2017b].

A mí me da exactamente lo mismo el tema del terremoto, la historia del muro y el terremoto. A mí me interesa la historia del muro, la memoria del muro, lo que el muro representa. Quizá se haya caído con el terremoto, una tragedia [exdetenido de Villa Grimaldi 2017b].

Contar con la posibilidad de tener estos espacios faltantes [...], eso también permite hacer otro uso del muro, que quizá no se podría hacer si quizá estuviera todo restaurado de la forma original. Entonces, yo pienso que quizá esto daría 


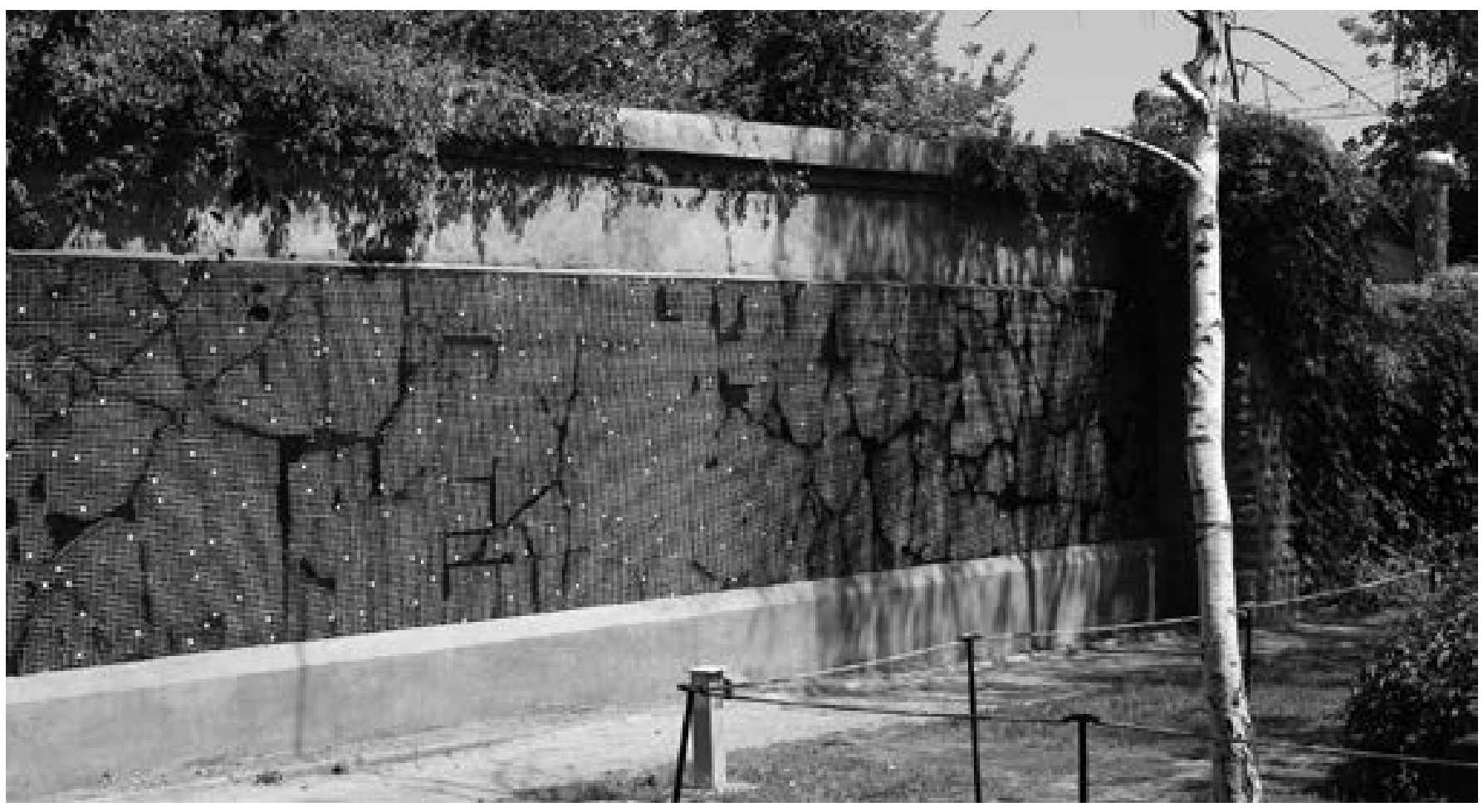

FIGURA 4. Muro de Mosaicos de Villa Grimaldi luego de su restauración (Fotografía: Daniel Rebolledo, 2018).

potencial al trabajar el muro como objeto, en una actividad distinta que no sea en un recorrido pedagógico y eso quizá permite, como un trabajo más particular. [...] eso también le permite, quizá, ser más versátil, pensando en una forma de distintos usos del muro, no sólo su referencia en un recorrido, por ejemplo [educadora de Villa Grimaldi 2017b].

creo que sería más impactante presentar el muro, lo que se cayó, tal como está y con los espacios faltantes, porque, de alguna manera, explicar que ese desastre, que es la caída del muro, no se ha reconstruido el muro porque el desastre es mayor [...]. Yo creo que el muro podría representar la fractura que se produce en esta sociedad, el terremoto terrible que significa el tener gente presa política, muertos aquí. Eso, probablemente, ese muro podría relevarlo, el terremoto no tiene significado, porque nadie murió por cuenta del terremoto [representante comunidad local 2017b].

En general, las diferentes perspectivas sobre la restauración coincidieron en la posibilidad de disponer de un espacio que permitiera abordar algunos complejos temas asociados con las memorias de las violaciones a los derechos humanos. En definitiva, la principal tendencia fue por la segunda opción, es decir, visibilizar las áreas faltantes, pensando en utilizar estos vacíos para añadir al muro un relato sobre las formas de construir memoria en relación con los silencios e intentos de ocultar las violaciones a los derechos humanos. En consideración de aquel consenso, al finalizar el último encuentro se acordó nombrar la obra como "Fragmento de memorias rescatadas".
Sobre aquella decisión, finalmente, el equipo de restauración procedió a ejecutar las labores de restablecimiento de los mosaicos caídos, procurando no reemplazar las piezas ausentes. La Figura 4 muestra el proceso restaurativo terminado. Este nuevo Muro de Mosaicos se presentó públicamente el 11 de septiembre de 2017.

\section{Reflexiones finales}

Los encuentros participativos "ejercicios de memoria" representaron una instancia pionera en la gestión museográfica del sitio de memoria Parque por la Paz Villa Grimaldi. Con la opinión de actores sociales relativos a diversos periodos históricos y usos del lugar, se acordó un formato de restauración que recogiera las memorias vinculadas con Villa Grimaldi en tanto centro de detención política y sitio de memoria. Si bien, inicialmente, los encuentros buscaban dialogar en torno de las opciones de restauración, en cada uno surgieron otros temas relacionados con las estrategias educativas de diversos espacios del sitio, el cuidado del patrimonio local y los sentidos de los ejercicios de conmemoración en el presente.

Tal como la metodología de la museología participativa indica, más allá del resultado de gestión que se determine, la incorporación de distintos agentes a la administración regular del museo no sólo enriquece las políticas museográficas, sino genera vínculos entre la comunidad y su patrimonio (Alemán 2011: 116-117). En este caso, la restauración del Muro de Mosaicos de Villa Grimaldi se 
estableció como un consenso que logró articular la memoria de las víctimas de la represión política, la valoración de la comunidad local y las estrategias pedagógicas de enseñanza del pasado reciente. Al ser seleccionada la segunda opción de restauración, cabe interpretar que, en el debate acerca de cómo construir memoria entre las alternativas de "memoria literal y ejemplar" (Marchesi 2018: 285), primó esta última, que destaca la relevancia de la relación pasado-presente y valores como la educación, el aprendizaje y la sensibilización para los actores y comunidades del Parque por la Paz.

\section{Referencias}

Aguilera, Carolina

2011 "Proyecto de Museo en Villa Grimaldi. Una apuesta participativa de construcción", en Carolina Aguilera y Carolina Cárcamo (eds.), Ciudad y memorias. Desarrollo de sitios de conciencia en el Chile actual, Santiago, Ediciones de la Corporación Parque por la Paz Villa Grimaldi, pp. 100-109. 2013 "Santiago de Chile visto a través de espejos negros. La memoria pública sobre la violencia política del período 19701990, en una ciudad fragmentada", Bifurcaciones 14: 1-13.

Aguilera, Darío

2012 "Construyendo museo junto a la comunidad", Museos 31: 34-37.

Alegría, Luis

2011 "Patrimonio y atrocidad", en Daniela Marsal (comp.), Hecho en Chile. Reflexiones en torno al patrimonio cultural, Santiago, Ediciones Marval, pp. 293-320.

Alemán, Ana María

2011 "Los museos comunitarios participativos. Una aproximación a la nueva museología", Cultura 25: 113-125.

Bascuñán, Karen

2018 "Educación en derechos humanos en el contexto de la posdictadura en Chile. La propuesta desde el sitio de memoria Parque por la Paz Villa Grimaldi", en Abraham Magendzo y Paulina Morales (eds.), Pedagogía y didáctica de la Declaración Universal de los Derechos Humanos a setenta años de su promulgación (1948-2018), Santiago, Ediciones Universidad Academia de Humanismo Cristiano, pp. 107-115.

Cabeza, Ángel

2017 "Introducción al Patrimonio de los Derechos Humanos en Chile", en Ángel Cabeza, Ana Cárdenas, Miguel Lawner, Pablo Seguel y Javiera Bustamante, Patrimonio de la memoria de los derechos humanos en Chile, Santiago, Consejo de Monumentos Nacionales, pp. 11-18.

Corporación Parque por la Paz Villa Grimaldi 2010 Guion final Audioguías en español. Santiago, Área Museo-Corporación Parque por la Paz Villa Grimaldi.

Feld, Claudia

2011 "Prólogo. La memoria en su territorio", en Béatrice Fleury y Jacques Walter (comps.), Memorias de la piedra. Ensayos en torno a lugares de detención y masacre, Buenos Aires, Ediciones Ejercitar la Memoria, pp. 9-20.
Educadora de Villa Grimaldi

2017a Videograbación del Segundo Encuentro Participativo del proyecto "Puesta en valor de la memoria histórica de Villa Grimaldi", 19 de julio, Santiago de Chile. Registro realizado por el Área Museo de la Corporación Parque por la Paz Villa Grimaldi.

2017b Videograbación del Segundo Encuentro Participativo del proyecto "Puesta en valor de la memoria histórica de Villa Grimaldi", 19 de julio, Santiago de Chile. Registro realizado por el Área Museo de la Corporación Parque por la Paz Villa Grimaldi.

Exdetenido de Villa Grimaldi

2017a Videograbación del Primer Encuentro Participativo del proyecto "Puesta en valor de la memoria histórica de Villa Grimaldi", 19 de julio, Santiago de Chile. Registro realizado por el Área Museo de la Corporación Parque por la Paz Villa Grimaldi. 2017b Videograbación del Primer Encuentro Participativo del proyecto "Puesta en valor de la memoria histórica de Villa Grimaldi", 19 de julio, Santiago de Chile. Registro realizado por el Área Museo de la Corporación Parque por la Paz Villa Grimaldi.

Garcés, Mario

2009 "Conceptos de patrimonio, ciudadanía y memoria", en VV. AA., Tercer Congreso de Educación, Memoria y Patrimonio. Aprendizaje en Espacios Alternativos de Educación Patrimonial, Santiago, Dibam/CECA Chile, pp. 171-176.

Lavabre, Marie Claire

2018 "Memoria colectiva", en Ricard Vinyes (dir.), Diccionario de la memoria colectiva, Barcelona, Gedisa, pp. 278-281.

Lawner, Miguel

2017 "Arquitectura y memoria histórica", en Ángel Cabeza, Ana Cárdenas, Miguel Lawner, Pablo Seguel y Javiera Bustamante, Patrimonio de la memoria de los derechos humanos en Chile, Santiago, Consejo de Monumentos Nacionales, pp. 11-18.

López, Loreto

2010 "Lugares de memoria de las violaciones a los derechos humanos: más allá de sus límites", en Tania Medalla, Alondra Peirano, Olga Ruiz y Regine Walch (eds.), Recordar para pensar. Memoria para la democracia, Santiago, Ediciones Boll Cono Sur, 57-66.

Marchesi, Aldo

2018 "Memoria ejemplar y literal", en Ricard Vinyes (dir.), Diccionario de la memoria colectiva, Barcelona, Gedisa, pp. 284-285.

Orellana, María Isabel

2007 "Patrimonio y comunidad: reflexión institucional y participación ciudadana", en Dibam, Museos en obra. IX Seminario sobre Patrimonio Cultural, Santiago, Ediciones de Dibam, Gobierno de Chile, pp. 192-209.

Pozo, José del 2018 Diccionario histórico de la dictadura cívico-militar en Chile, Santiago, Editorial LOM.

Representante comunidad local

2017a Videograbación del Tercer Encuentro Participativo del proyecto "Puesta en valor de la memoria histórica de Villa Gri- 
maldi", 27 de julio, Santiago de Chile. Registro realizado por el Área Museo de la Corporación Parque por la Paz Villa Grimaldi. 2017b Videograbación del Tercer Encuentro Participativo del proyecto "Puesta en valor de la memoria histórica de Villa Grimaldi", 27 de julio, Santiago de Chile. Registro realizado por el Área Museo de la Corporación Parque por la Paz Villa Grimaldi.

Salazar, Gabriel

2013 Villa Grimaldi (Cuartel Terranova), Santiago, Editorial LOM.

Santos-Herceg, José

2016 "Geografía humana del horror. Agentes, detenidos y transeúntes", en Carolina Pizarro y José Santos-Herceg (comps.), Revisitar la catástrofe. Prisión política en el Chile dictatorial, Santiago, Ediciones Pehuén/Instituto de Estudios Avanzados-Universidad de Santiago de Chile, pp. 167-186.

Seguel, Pablo

2017 "La dimensión política y social de los procesos de puesta en valor del patrimonio de la memoria de las violaciones a los derechos humanos en Chile. 1996-2016", en Ángel Cabeza, Ana Cárdenas, Miguel Lawner, Pablo Seguel, Javiera Bustamante, Patrimonio de la memoria de los derechos humanos en Chile, Santiago, Consejo de Monumentos Nacionales, pp. 25-35.

Silva, Macarena, y Fernanda Rojas

2011 "El manejo urbano-arquitectónico de la memoria urbana traumatizada", en Carolina Aguilera y Carolina Cárcamo (eds.), Ciudad y memorias. Desarrollo de sitios de conciencia en el Chile actual, Santiago, Ediciones de la Corporación Parque por la Paz Villa Grimaldi, 2011, pp. 78-84.

UNESCO

s. f. Qué es el patrimonio cultural inmaterial, documento electrónico disponible en [https://ich.unesco.org/doc/src/01851ES.pdf], consultado en julio de 2017.

Yocelevzky, Ricardo

2002 Chile: partidos políticos, democracia y dictadura. 19701980, Santiago, Fondo de Cultura Económica.

\section{Síntesis curricular de/los autor/es}

\section{Omar Sagredo Mazuela}

Área Museo de la Corporación Parque por la Paz Villa Grimaldi, Chile omar.sagredo@villagrimaldi.cl

Politólogo, licenciado en ciencia política y relaciones internacionales y magíster en estudios internacionales (Universidad de Santiago de Chile [Usach]). Profesional del Área Museo y encargado del Archivo Oral de la Corporación Parque por la Paz Villa Grimaldi, en Chile. Docente de la cátedra "Transición a la democracia y derechos humanos: Chile y el Cono sur americano", de la carrera de Ciencia Política de la Universidad Alberto Hurtado. 